\title{
Resource use in neonatal cardiac surgery: Lacking details
}

\author{
Ming-Sing Si, MD
}

\author{
From the Section of Pediatric Cardiovascular Surgery, Department of Cardiac Surgery, University of Michigan, \\ Ann Arbor, Mich. \\ Disclosures: Author has nothing to disclose with regard to commercial support. \\ Received for publication Feb 12, 2018; accepted for publication Feb 20, 2018; available ahead of print March 28, \\ 2018. \\ Address for reprints: Ming-Sing Si, MD, 11-735, C.S. Mott Children's Hospital, SPC 4204, 1540 E Hospital Dr, \\ Ann Arbor, MI 48109-4204 (E-mail: mingsing@umich.edu). \\ J Thorac Cardiovasc Surg 2018;155:2615-6 \\ $0022-5223 / \$ 36.00$ \\ Copyright (C) 2018 by The American Association for Thoracic Surgery \\ https://doi.org/10.1016/j.jtcvs.2018.02.055
}

Neonatal cardiac surgery in the United States comes with significant cost. ${ }^{1}$ Factors associated with increased resource use in neonatal cardiac surgery include gestational age, intrauterine growth restriction, and extracardiac comorbid conditions. ${ }^{2,3}$ Further, admission to a dedicated cardiac intensive care unit (CICU) was found to be associated with decreased resource use in a single-institution study. ${ }^{4}$ Johnson and colleagues, ${ }^{5}$ the same group that conducted that earlier study, ${ }^{4}$ report in this edition of the Journal a confirmation of their initial findings with a multicenter study of data from the Pediatric Hospital Information Systems (PHIS) database.

Johnson and colleagues ${ }^{5}$ used the PHIS database to determine the possibility of 2 associations in the setting of neonatal cardiac surgery: (1) association of intensive care unit admission location with hospital costs and resource use and (2) association of intensive care unit admission location with mortality. Although not explicitly stated, their hypotheses appear to be related to their initial single-center findings ${ }^{4}$ that at least the first association exists nationwide. With data from the PHIS database and cardiac surgical procedure codes, they were able to identify neonates ( $<30$ days of age) with a Risk Adjusted Classification for Congenital Heart Surgery score of 2 through 6 undergoing cardiac surgery from January 2004 through December 2013 to include in their study ( $\mathrm{n}=19,984$ neonates). The admission location was defined as the CICU, neonatal intensive care unit (NICU), or pediatric intensive care unit (PICU). Because of certain charging practices resulting in PICU and CICU charges being combined, only a comparison between the CICU and the NICU was performed in the primary analysis, whereas a secondary analysis compared the PICU and the NICU. The primary outcome analyzed was total hospital cost, and secondary outcomes included preoperative length of stay (LOS), total hospital LOS, intensive care unit LOS, days of mechanical ventilation, and death before discharge.

Johnson and colleagues ${ }^{5}$ found that $39 \%$ of neonates were admitted to the CICU, $48 \%$ to the NICU, and $13 \%$ to the PICU. Consistent with the findings of their previous

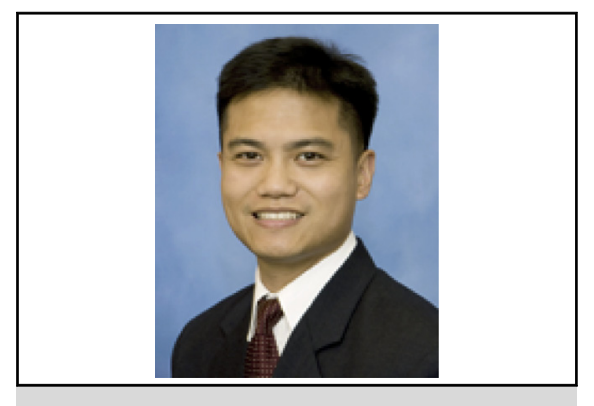

Ming-Sing Si, MD

Central Message

An association is discernible between a dedicated cardiac intensive care unit and decreased resource use in the setting of neonatal cardiac surgery.

See Article page 2606.

work, ${ }^{4}$ they found that admission to the CICU was associated with a significant cost reduction when compared with admission to the NICU. Further, admission to the CICU was associated with a shorter LOS and fewer days of mechanical ventilation. There were no differences in mortality between the intensive care unit defined groups. Johnson and colleagues ${ }^{5}$ conclude that admission to a specialized CICU results in decreased hospital costs and more efficient use of resources.

These findings are important, because they represent a factor that can be potentially modified in the care of these patients. Although the results are consistent with the previous study and thus are not unexpected, the shortcomings of this study need to be highlighted before using these data and conclusions as the rationale to change existing health care organizations and practices. First, the data from which the analysis and conclusions were made in this study were derived from the PHIS database, which is an administrative database. Administrative databases have several advantages: they are easy and inexpensive to obtain, they contain data on a large number of patients, and they reliably report such clinical outcomes as death. ${ }^{6}$ By virtue of their primary administrative purpose, however, administrative databases have the main shortcoming of lacking the clinical details needed for a comprehensive understanding of the main events that occur. In this particular study, the PHIS database fails to provide a reason that any given patient is admitted to the NICU rather than the CICU. Excluding prematurity, one can speculate that the common reasons for initial admission to the NICU are that neonatal lines or invasive procedures 
need to be performed and that additional diagnostic studies are needed in a stable preoperative patient who does not need to occupy a CICU bed (thus making room for postoperative patients). These neonates then undergo their cardiac surgical repair and are then taken care of in the CICU. In their study, Johnson and colleagues ${ }^{5}$ confirm that of the transfers that do occur between intensive care units, it is usually from the NICU to the CICU or PICU after surgery. Although they report that patients admitted to the NICU spent a median of $55 \%$ of their time in the NICU, it is unclear from the data given how many patients actually stayed in the NICU after surgery. The impact of the study of Johnson and colleagues ${ }^{5}$ is to convince practitioners and hospital systems of the importance of specialization to reduce resource use. Although there is little argument with the claim that specialization impacts resource use, this statement in the setting of this study would imply that preoperative specialized cardiac care is lacking in institutions performing neonatal cardiac surgery because patients are admitted to the NICU, which seems unlikely. Rather, the reasons for admission to the NICU before neonatal cardiac surgery may be related to other factors, as mentioned previously.

Many clinical, nonclinical, and institution-specific factors can influence where neonates with critical congenital heart disease are admitted preoperatively. When it comes to the analysis of preadmission location influence on resource use of neonates undergoing cardiac surgery, the rationale behind each patient's admission and transfer would need to be defined. For example, if a patient were noted to be admitted to the NICU because a bed was needed in the CICU for a patient who had undergone an elective surgical procedure, then the cost of admitting to the NICU rather than the CICU could be compared with the estimated cost of not doing the elective surgery. Hospitals would then be able to determine the break-even point when such a strategy would not be cost-effective, and this could provide a more convincing rationale to expand CICU capacity.

\section{References}

1. Smith AH, Gay JC, Patel NR. Trends in resource utilization associated with the inpatient treatment of neonatal congenital heart disease. Congenit Heart Dis. 2014;9:96-105.

2. Bishop NB, Zhou TX, Chen JM, Ward MJ, Carroll SJ. The impact of gestational age on resource utilization after open heart surgery for congenital cardiac disease from birth to 1 year of age. Pediatr Cardiol. 2013;34:686-93.

3. Graf R, Ghanayem NS, Hoffmann R, Dasgupta M, Kessel M, Mitchell ME, et al. Impact of intrauterine growth restriction on cardiac surgical outcomes and resource use. Ann Thorac Surg. 2015;100:1411-5.

4. Johnson JT, Tani LY, Puchalski MD, Bardsley TR, Byrne JL, Minich LL, et al. Admission to a dedicated cardiac intensive care unit is associated with decreased resource use for infants with prenatally diagnosed congenital heart disease. Pediatr Cardiol. 2014;35:1370-8.

5. Johnson JT, Wilkes JF, Menon SC, Tani LY, Weng HY, Marino BS, et al. Admission to dedicated pediatric cardiac intensive care units is associated with decreased resource use in neonatal cardiac surgery. J Thorac Cardiovasc Surg. 2018;155: 2606-14.e5.

6. Hashimoto RE, Brodt ED, Skelly AC, Dettori JR. Administrative database studies: goldmine or goose chase? Evid Based Spine Care J. 2014;5:74-6. 